\title{
Bolívar soy yo, de Jorge Alí Triana: tour de forcé entre dos imaginarios ${ }^{*}$
}

\author{
Juan Felipe Barreto Salazar ${ }^{1}$ \\ Yudis Contreras Martínez ${ }^{2}$ \\ Universidad de Cartagena
}

\section{Resumen}

El siguiente trabajo busca mostrar la tensión presente entre la significación de Simón Bolívar en la consciencia histórica -a partir de una imagen heredada de modo patrimonial por estamentos estatales y artefactos academicistas y ortodoxos-, y la presentación del mismo sujeto histórico en el horizonte de la ficción fílmica. Para ello se propone como ejemplo el filme de Jorge Alí Triana, Bolívar soy yo (2001), en el cual se muestra la anulación de un Bolívar heroico a nombre de la imagen abierta desde la naturaleza deformante del cine: un Bolívar más personal, más humano, metáfora de

\begin{abstract}
The following article aims to show the tension present between the significance of Simon Bolivar in the collective history -from an inherited image constructed by the State and the orthodox and academic sector- and the presentation of the same historical subject in the realm of film fiction. To illustrate this tension, we will use as an example the film by Jorge Ali Triana, Bolívar soy yo (2001) in which the annulment of the historical figure of bolivar is shown by the lenses of the transforming nature of cinema: giving Bolívar a more personal, and humane look, is a metaphor of disconti-
\end{abstract}

\footnotetext{
* "Bolívar soy yo, by Jorge Alí Triana: tour de forcé between two imaginaries" Recibido: 2 de agosto de 2013 - Aprobado: 10 de septiembre de 2013

${ }^{1}$ Profesor de filosofía de la Universidad de Cartagena. Filósofo de la Universidad del Valle, Magíster en Filosofía de la Pontificia Universidad Javeriana de Bogotá. Director del Grupo de Investigaciones Estéticas y Culturales "Signos Culturales". Autor del libro La semiótica del arte (2008). e-mail: fellinibarreto@gmail.com

${ }^{2}$ Licenciada en Lenguas Modernas de la Universidad del Atlántico, Magíster en Literatura Hispánica de la Universidad de Arkansas (E.E.U.U.) y Doctora en Literatura Hispánica de la Universidad de Indiana (E.E.U.U.). e.mail: ycontrerasm@ unicartagena.edu.co
} 
la discontinuidad, la fragmentación y el caos de una sociedad no unida como nación, sino en proyecto de ello.

Palabras clave: Simón Bolívar, historia, cine, hermenéutica cinematográfica, semiótica cultural, nación. nuity, fragmentation, and chaos in a society not together as nation, but as a project of one.

Keywords: cinema, hermeneutics, cinematography, cultural semiotics, History, nation.

\section{Introducción}

Desde principios del siglo XIX en Colombia y Venezuela la imagen tradicional de Simón Bolívar que prevalece en la memoria colectiva es la que se ha presentado desde los monumentos en plazas públicas, museos, estamentos gubernamentales y en textos de historia patria. Un Bolívar esculpido o pintado como a un guerrero vencedor: general del ejército, con uniforme militar, usualmente ajustado a un caballo como si se dirigiera al campo de batalla. A ese Bolívar guerrero se le reconoce como "El Libertador", y es visto como el líder de la gesta independentista del siglo XIX ${ }^{3}$. Con esta caracterización, el ese Bolívar victorioso gana un gran valor social y cultural, ya que se le relaciona con los triunfos de las independencias nacionales: la de Colombia, con la batalla de Boyacá, el 7 de Agosto de 1819, y la de Venezuela, con la batalla de Carabobo, el 24 de Junio de 1821. Esa imagen de un Bolívar libertario, así mismo, es muy valiosa, porque representa la soberanía nacional obtenida por los criollos en contra de la Corona española, y como tal, marca el inicio de un mundo nuevo para los pueblos latinoamericanos en los cuales lideró la gesta independentista.

Exaltando la valentía de Bolívar al oponerse al régimen político de España, el historiador colombiano Germán Arciniegas (1984) lollamó "el guerrero del siglo XIX". Con la misma intención, representantes políticos y escritores latinoamericanos lo han denominado "mito viviente", "Júpiter olímpico" y con muchos otros apelativos que enaltecen su tarea libertaria (Carrera, 1989). Esa valoración que se ha hecho de Bolívar como estratega militar por parte de estamentos

\footnotetext{
${ }^{3}$ El epíteto "El Libertador" le fue otorgad a Simón Bolívar por la municipalidad de Caracas a su regreso de lo que se conoce como "La Campaña Admirable", con la cual se conformó en Venezuela la primera república. De allí en adelante, y con el fin de homenajear su función militar, este fue el seudónimo con el que mayoritariamente se le reconoció a Bolívar.
} 
oficiales y textos de historia ha sido útil a muchos representantes políticos latinoamericanos para proyectarlo como su líder.

Bolívar también ha sido altamente exaltado como un fundador de naciones y como tal se destaca su imagen de estadista. Ha sido muy enunciado su sueño de querer conformar una patria grande, a la que llamaría "La Gran Colombia", nación que surgirá al unir cinco países latinoamericanos. Su deseo era obtener un gran poder político y económico para conformar en el sur del continente americano un país que fuera tan poderoso como los Estados Unidos. Con el fin de resaltar su imagen de estadista son citados una y otra vez sus postulados políticos expresados en "La Carta de Jamaica" (1965), en el Congreso de Angostura (1975) y el Congreso Anfictiónico de Panamá (1826). La propagación de un Bolívar libertario o estadista hecha por diversos líderes latinoamericanos ha tenido como objetivo primordial fomentar una unidad nacional entre los distintos ciudadanos.

Esa imagen de un Bolívar representante de una unidad nacional no se percibe de igual manera desde los textos ficcionales contemporáneos de Colombia y Venezuela. Desde el cine y la literatura que surge a partir de la segunda mitad del siglo XX se inicia una revisión de la imagen del "Bolívar victorioso". La razón es hacer que, en la mayoría de los casos, ni la imagen ni el nombre Bolívar se relacionen con epítetos que exalten su labor en la gesta independentista o su figura de estadista. La función de los textos ficcionales es hacer de Bolívar un héroe afín a los ciudadanos que representa. Bolívar es un hombre enfermo y muy debilitado, es un indocumentado en la novela $L a$ ceniza del Libertador (1987), de Fernando Cruz Kronfly (1987); es la proyección delirante de un desquiciado, Santiago Miranda, en el filme Bolívar: soy yo, de Jorge Alí Triana (2001), y es un colibrí, según la novela Yo, Bolívar rey (1986), de Caupolicán Ovalle.

En estas obras se busca anular la imagen de un Bolívar heroico que representa una unidad nacional y que muestra a través de sí mismo una nación estable y soberana. En contraposición, el Bolívar humanizado, unas veces enfermo, alucinante o confundido, busca mostrar las grietas que esa unidad nacional afronta. El Bolívar que acogen los textos de ficción es el símbolo que representa una nación en conflicto. En medio de la globalización, ante la gran influencia de los medios de comunicación, tomando en cuenta las múltiples diferencias políticas e ideológicas de los distintos sujetos que viven en Colombia y Venezuela, los textos ficcionales buscan delinear un Bolívar que exista en medio de una unidad nacional fallida. Un 
espacio en donde los ciudadanos luchan porque se respeten los derechos civiles y la verdadera soberanía nacional.

En cualquier caso, el preconcepto histórico que tengan los ciudadanos sobre ese Bolívar heroico será una herramienta útil para los textos ficcionales, los cuales rescriben sobre las líneas trazadas por la historia oficial. Desde una imagen que representa a los colombianos o venezolanos se ha planteado una unión ciudadana al concebir a Bolívar como modelo, y por lo tanto, como sustento de lo que debe ser la nación. El biógrafo Carrera Damas (1989) anota, por ejemplo, que la imagen de Bolívar es sostenida como "una unidad nacional al convertirlo en reivindicación del principio del orden; en factor de gobierno, como manadero de inspiración política; y en factor de superación nacional, como religión de la perfección moral y cívica del pueblo" (43).

El investigador norteamericano Christopher Conway (2003), por su parte, a través de distintos monumentos y textos literarios venezolanos, analiza cómo la imagen de Bolívar se ha usado para mantener un discurso de género, identidad nacional y lo que él, desde nuevas representaciones artísticas, ha leído como el fracaso de la modernidad. Conway analiza, desde la literatura, cómo la imagen de Bolívar es usada para reafirmar el concepto dominante de género en una sociedad patriarcal. Revisa las reacciones que se generan por parte de líderes políticos en contra de representaciones que intenten romper el esquema de Bolívar visto como una figura masculina y dominante. En un paralelo con la imagen plástico-visual del monumento, observa en las revisiones que se hacen desde textos escritos en torno a la figura tradicional de Bolívar el correlato de la representación de un sistema político roto, contaminado y caótico.

Al contextualizar varios textos ficcionales de Colombia y Venezuela en las últimas décadas del siglo XX y principios del XXI encontramos que esta nueva mirada a la idea del Bolívar heroico indica que en ellos se alegoriza la imagen de la nación. En la novela La ceniza del libertador se observa, por ejemplo, que la imagen de Bolívar se desmitifica a partir de una narración de la historia basada en la memoria y en el papel del archivo. De igual manera, a través de la imagen de Bolívar se sugiere una agencia de los ciudadanos. Esto es posible al volverlos receptores de la imagen ficcional que se muestra desde el "final abierto" que presentan obras como la película Bolívar, soy yo y la novela Yo, Bolívar rey. En estos dos textos, en particular, prima la "fragmentación del discurso y de la imagen" de un discurso bolivariano en torno a la unidad nacional, y por lo tanto, el público 
es abocado a poner las fichas en orden, conectando el presente y pasado nacional.

Las apropiaciones de Bolívar que hacen los textos de ficción contemporáneos subvierten la idea del discurso hegemónico. Con las nuevas caracterizaciones, dichos textos intentan ganar un reconocimiento desde una nueva escritura que muestra a través de distintos tópicos estéticos un constante paralelismo entre Bolívar y sus conciudadanos en distintos momentos de crisis. En ese sentido, la imagen de Bolívar que se evoca en Colombia y Venezuela ya no se lee como la de "El Libertador", sino que gana nuevos significados, indicando que se ha desasociado de su valor tradicional y como tal es visto como un "significante vacío" (Laclau, 2005). Es decir, que su imagen no logra encerrar todos los espacios, individuos o conceptos que hegemónicamente se intentan inscribir desde su configuración de héroe nacional mediante una postura lineal. La imagen de Bolívar hecha desde la representación nacional falla en su connotación directa o alegórica en cuanto se plantee que Bolívar debe ser reconocido sólo por medio de su epíteto de "El Libertador", o como padre fundador de la nación colombiana o venezolana.

A medida que se entra en el análisis de un Bolívar ficcional se observa que los textos de ficción también van ajustando la imagen de Bolívar a nuevos requerimientos. El Bolívar de los textos ficcionales indica que en el entorno social y político de fines del siglo XX y las primeras décadas del XXI ya no tiene una sola faceta, sino varias capas y surge como una respuesta fidedigna al espacio social y político en el que se le reconoce como héroe nacional. Por este motivo se le convertirá en un exiliado, un desplazado o un hombre solitario y confundido. Bolívar será visto como un hombre común y corriente que vive situaciones similares a las que viven, en uno u otro momento, los ciudadanos de Colombia o Venezuela a lo largo de su historia sociopolítica.

Es en este sentido como el presente trabajo busca dar un paso adelante en la investigación, al interpretar en una obra de ficción, un filme, la tensión entre las significaciones iluminadas a partir de la tradición histórica y las significaciones que proponen los textos artísticos. La película de Jorge Alí Triana, Bolívar soy yo (2001), debe permitir develar que, más allá de la configuración tradicional de corte ideológico del "Bolívar patrimonial", puede coexistir la de un "Bolívar ficticio", siempre reinventable, y paradójicamente, tal vez más "real", o al menos, más humano. 


\section{Bolívar soy yo: recodificación de un individuo desde el horizonte de la experiencia estético/artística de los receptores}

Puntualmente, en el filme de Jorge Alí Triana existen tres aspectos que merecen ser analizados: 1) la rescritura de la historia, 2) la razón de ser del rol quijotesco con el que Santiago representa a Bolívar y 3) la importancia que tienen los medios de comunicación en la construcción de una nueva imagen. Estos tres puntos nos permitirán entrar en un análisis en torno a cómo la película deshace la imagen de un Bolívar heroico que representa una "unidad nacional" y más bien permite aproximaciones más abiertas (equivocidad y ambigüedad) a este personaje histórico. En el contrapunto historia-ficción, el Bolívar quijotesco gana hondura reflexiva, ya que promueve un discurso más crítico en torno al Bolívar/hombre y su relación con la nación.

El siguiente análisis del filme de Triana, a la luz de las anteriores cuestiones, se hace entonces posible desde la óptica de que la naturaleza artística del filme sitúa al espectador en un horizonte de lectura de los objetos mucho más abierto que en el plano base de la interpretación corriente, siempre más denotativo. La obra, por su enorme cantera de posibilidades comunicativas instanciadas a raíz de su configuración morfo-sintáctica, plantea nuevos retos y salidas a quien lee. Y mucho más, cuando se habla en términos de equivocidad o apertura en los textos artísticos:

El lector se excita, por tanto, frente a una libertad de la obra, a su posibilidad activa e infinita de proliferación, frente a la riqueza de sus aditamentos internos, de las proyecciones inconscientes que involucra, de la invitación que le hace la tela a no dejarse determinar por los nexos causales y por las tentaciones de lo unívoco, comprometiéndose en una transacción rica en descubrimientos cada vez más impredecibles (Eco, 1984: 181).

De este modo, la construcción de la imagen de Simón Bolívar se hace efectiva para el lector estético, en el giro que aprieta cada vez más dos vías de interpretación, la ceñida a los textos puramente históricos (manuales, documentos, archivos, etc.), y la de la ambigüedad. Se trata de un tour de forcé, que no desplaza el horizonte más unívoco de interpretación general, el cual pone sus intereses en el modo como realmente ocurrieron los hechos, sino que lo tensiona con el de la ambigüedad, para a partir de ahí buscar otorgar más significación en términos críticos o problemáticos, sin menoscabar con ello en las cuotas de fruición estética. En últimas, se hacen 
coincidir dos realidades que se carcomen simbólicamente, pero que se autonomizan a partir de su "ajena".

En definitiva, los siguientes tres niveles de análisis propuestos para la obra de Triana, develan dos elementos vinculados, uno de corte artístico, y posiblemente más explícito, y otro metafísico, que mira desde el fondo. Por un lado, el carácter siempre ambivalente a que tienden las obras de arte, particularmente las modernas, y por otro, el carácter problemático de la concepción de la verdad respecto a la realidad, las cosas y su representación histórica, estética, o psicológica. Esto último, porque el vaivén vacilante de las obras que amaga entre la forma como debería ser entendida la realidad y cómo podría entendérsele, convoca y provoca a sus lectores, siempre distintos históricamente, a repensar la realidad, a desasegurarla, a ponerla en crisis, a reescribirla

\section{Reescribiendo la historia, reescribiendo un personaje}

Revisando el discurso histórico que hace Santiago (el personaje del filme) hay una constante intertextualidad que muestra la relación entre historia y ficción, y que se aprecia desde el principio hasta el final de la película. Como ejemplos específicos, podemos partir de la primera escena de la película, cuando Santiago empieza pronunciando la última proclama de Bolívar y luego la interrumpe diciendo: "corten, corten, que Bolívar no murió así". El énfasis en la película pareciera estar en el fusilamiento que se le va a hacer a Bolívar, y al cual Santiago se rehúsa, porque, según lo escrito en los textos de historia, él murió enfermo y rodeado de muy pocos amigos.

El propósito del final propuesto por el director consiste en que un Bolívar que muere fusilado permitiría presentar una historia más dramática. Desde esta perspectiva, el director centra su interés en un producto llamativo para el espectador medio. Igualmente, un Bolívar secuestrado como el que presenta Triana, también es parte de esa estrategia comercial con respecto a cuál es el héroe nacional que se debe representar, uno que evoluciona con el tiempo y que se debe caracterizar según sea la imagen que les interesa a los medios de comunicación. También el director expresa que quiere mostrar una imagen que sea atractiva para el público y que es por eso que ha escrito sobre un Bolívar donjuanesco.

Haciendo una reflexión sobre la representación que debe hacer de Bolívar, Santiago alude a que tanto el final que plantea el director, así como la vida amorosa que muestra de Bolívar, son parte de una farsa. Con esta anotación, Santiago implícitamente está diciendo 
que la historia que se está mostrando de Bolívar no es real: "no quiero continuar con esta farsa". Esa idea que expresa tiene un doble propósito, y no pareciera referirse sólo al papel que se niega a representar, sino también a la historia que se ha contado en torno a Bolívar por mecanismos de estado.

La relación entre historia y ficción muestra entonces que la verdadera nueva historia que quiere contar Santiago es un metatexto del discurso histórico, en cuanto su actuación funciona como una crítica a la escritura bolivariana que se ha presentado desde la historia oficial. Esto se evidencia también en el discurso que Santiago debe leer en un desfile patriótico, el cual comienza como si fuera una copia de una proclama de Bolívar, pero poco a poco Santiago va ajustándolo a uno que haga referencia al presente nacional de Colombia en el momento en que se presenta la película (2001). Para Santiago, la figura de Bolívar será significativa en la medida en que la historia que se reescribe permita mejorar las situaciones que viven los colombianos en torno a la educación, la salud, etc.

La reescritura de la historia también se da desde la agencia que indirectamente se le pide cumplir al público. Mediante un flash back que conecta el presente y el pasado, y que pide juntar distintas partes, la película aboca al público a sacar sus propias conclusiones con respecto a la historia de Bolívar que se presenta. Así se genera una tensión para quienes desde la obra de Triana encuentren un Bolívar moldeable a cada situación política y social, y otros que vean un Bolívar que rechaza salir de su representación permanente de héroe independentista. En esa dualidad que genera Santiago se invita al público a pensar cuál es el Bolívar que más le conviene a la nación, el que muestra Santiago en su recorrido por La Plaza de Bolívar - uno que se ha quedado en la soledad de su estatua-, o uno que, como Santiago, haga parte activa del presente. De las conclusiones que extraiga el público se podrá pensar en cuál Bolívar creen los colombianos: en uno que sigue representando una unidad nacional, que ahora es vista como fallida, o en uno que entra a hacer parte de los distintos grupos sociales, los actores, la familia, los políticos, las fuerzas armadas, etc.

Hay también una solicitud de participación del público en la conexión que debe establecerse entre el principio y el final de la historia. Un final abierto que deja la historia de Santiago y de Bolívar como inconclusa indica que el público deberá conectar el principio con el final de la película y preguntarse qué significa la señal de "corte" que aparece en ambos casos. Como se ha mencionado previamente, en la primera escena Santiago hace una solicitud de "corte" y abandona su 
rol de Bolívar donjuanesco. En la escena final de la película, Santiago, muy mal herido, dice con voz agonizante "corten", y tras su orden aparece una señal que corrobora que ha llegado el final de la película. El final de la vida de Bolívar, y por consiguiente del presidente de la nación que se encontraba con él, se ha dado a causa de un enfrentamiento entre el ejército nacional y la guerrilla. Así, tanto Santiago/Bolívar como el presidente de la República aparecen como víctimas de un secuestro, y se muestra que a raíz de esta situación ambos mueren. Tras la muerte de Santiago, la película indica que así ha terminado la historia de Bolívar. En ese momento, el público podrá entonces decidir si la señal de "corte" que aparece al final de la película es sólo la culminación de la historia que se planteó desde las primeras escenas (momento en que Santiago supuestamente se sale del rol que se le ha asignado), o si tal señal muestra un hilo conductor que une toda la trama.

Ante la ambigüedad, el público deberá decidir cuál fue la verdadera historia de Bolívar que contó Santiago Miranda: la de un actor que hizo de actor todo el tiempo, o la de un actor que creyó desquiciadamente ser Bolívar mismo. En esa última escena cuando el público ve una señal de "corte", y a un Bolívar que en efecto muere fusilado, puede pensar que irónicamente el final del que Santiago quería huir es el final que ha tenido su personaje. Pero, además, se podría considerar, desde esa orden de "corte" que abre y cierra la película, si todo lo que representó Santiago en torno a Bolívar era meramente parte de un guion, y por consiguiente, sólo actuación. Por lo tanto, si tal representación de Santiago en torno a un nuevo Bolívar no fue más que una farsa, tal y como lo dijo Santiago, la farsa entonces hace referencia a cualquier versión inventada o vista como parte de un montaje, y no sólo como un desenlace inverosímil del Bolívar heroico.

La actuación de Santiago conlleva a analizar varios contrastes: verdad histórica-nueva historia; locura-cordura; ficción-realidad; actuación-representación. Así encontramos que la versión de un Bolívar histórico es puesta en escena desde la apariencia que lleva Santiago: botas, espada, vestido militar, etc. Esta caracterización remite al público a un Bolívar reconocible, y la nueva historia que propone la película surge de la imagen que prevalece en el imaginario colectivo. A partir de la intención de Santiago de involucrar a Bolívar en desfiles militares y reuniones políticas, se muestra que la nueva historia de Bolívar es escrita desde el presente y se narra teniendo en cuenta el conflicto nacional del siglo XXI: la falta de seguridad civil debida a la alta proliferación de grupos insurgentes. 
La representación de ese nuevo Bolívar lleva al público a examinar cuál es el papel que los ciudadanos del común le han asignado y que, como Santiago, hacen parte del entorno socio-nacional. Desde el conflicto que ha creado un actor enloquecido se puede pensar en cuál es el rol que le han otorgado los actores del conflicto armado, siguiendo el argot nacional en torno a los distintos colombianos que hacen parte del conflicto que se da en la nación. Además, si Santiago/ Bolívar es visto como un conciudadano más, su locura puede ser vista como el resultado del conflicto mismo en el que vive él y cualquier otro colombiano más. Esa barrera difusa entre locura y cordura de Santiago, y de un público que lo sigue como si fuera Bolívar, refleja a la vez la poca claridad existente en torno al conflicto armado por parte de los ciudadanos.

A partir de la representación que hace Robinson Díaz (el actor del filme) de un actor que representa un actor de una telenovela, hay una intencionalidad de mostrar lo importante que es el tema de la representación en la película. Este tema se reitera varias veces en la película: un momento específico se puede recordar cuando Santiago dice que él en realidad no cree ser Bolívar, pero que actúa como si lo fuera, porque el público así se lo pide. El énfasis que pone la película en el tema de la teatralidad es una forma indirecta de mostrar cómo el personaje histórico que Santiago representa ha sido construido precisamente desde ese elemento teatral. El actuar como Bolívar indica que a este personaje histórico se le ha representado de una manera, pero bien podría haber hecho otro papel, un donjuán, un loco, un personaje disfrazado, etc.

Así, pues, se genera un cuestionamiento en torno a la verdad histórica y al hecho de si en realidad es relevante que Bolívar aparezca de una forma o de otra, o si para los ciudadanos simplemente es importante que ayude a resolver las situaciones del presente. Detrás de la actuación de Santiago se aprecia que la ficción busca superar la realidad y hacer que el final del sueño bolivariano permita crear una nueva historia, con un mejor final, según lo expresa Santiago.

\section{Santiago Bolívar de la Mancha: la razón de una representación}

Pasando ahora a la pregunta del por qué el director basó su obra en ese Bolívar quijotesco, se debe tener en cuenta no sólo la razón de tal caracterización, sino también lo que ese Bolívar puede representar para los ciudadanos. Según Triana, su interés por hacer esta película está inspirado en lo ocurrido al actor colombiano Pedro Montoya, cuando él estuvo a cargo del documental histórico Bolívar el hombre de las dificultades (1982). El protagonista de esta serie se apropió 
tanto de su papel que creyó ser Bolívar mismo (Mora, 2009). En su reflexión sobre lo que le ocurrió a este actor, destaca que el mismo público colombiano que seguía la serie de televisión también veía y trataba a Pedro Montoya como si en realidad fuera Bolívar.

Para Triana, la creación del personaje principal de Bolívar soy yo tenía una doble función: un rol humorístico para el público que se reiría de las locuras de Santiago al creerse Bolívar, pero también reírse del propio público que aceptaba tal representación. Las acciones quijotescas de Santiago Miranda aparecen así como una crítica a los que aún esperan llevar a cabo el sueño de Bolívar, bien sea de conformar una patria grande, proponer cambios constitucionales o luchar por un mejor sistema educativo, porque aún lo esperan, le llevan flores, le cantan, le bailan, le hablan. Un ejemplo de esto es la escena en que las personas lo esperan a orillas del río Magdalena, lanzándoles flores al agua, bailando un vallenato y diciendo: "Viva nuestro Libertador". En la inversión de roles del loco y el cuerdo, como Don Quijote y Sancho, en Bolívar soy yo los cuerdos que son las personas del público pasan a ser los locos.

Al respecto, el escritor Diego Garzón (2002), refiriéndose al personaje que inspiró a Triana, explica cómo se daba esa situación por parte de un público que seguía a Montoya y que le alimentaba la idea de que él era Bolívar: "Después de la grabación de la histórica batalla de Boyacá, el párroco de Monguí difundió en todo el pueblo, a través de un altavoz 'la llegada de Bolívar', y los campesinos corrieron con gallinas, frutas, y regalos para llamar la atención del que creían héroe" (2). Así, la escena de la película en la que muchas personas van a recibir a Bolívar no es más que una réplica de lo que sucedió en la realidad.

Este reconocimiento de los seguidores de la serie de televisión se evidencia repetidas veces en la película, y, como ejemplo puntual, Santiago Miranda es llamado "Libertador" incluso por el mismo presidente de la República, quien lo recibe en el palacio presidencial y lo trata como si recibiera a Bolívar mismo. Este episodio, afirma Triana, corresponde a lo que en efecto le ocurrió a Pedro Montoya cuando filmó la serie de televisión antes mencionada. Corroborando lo que presenta Triana en su película, Diego Garzón anota:

El propio presidente Belisario Betancur lo invitó a su casa y al mostrarle la biblioteca le iba diciendo: 'Mire libertador: ¡cuántos libros sobre su vida!' [...] En el bicentenario del nacimiento de Bolívar, en 1983, los principales generales del Ejército colombiano lo invitaron a encabezar un desfile militar 
por las calles céntricas de Bogotá. Y lo hizo, vestido como Bolívar y a caballo, al frente de la tropa, y con la complacencia de los altos mandos militares y, por supuesto, de toda la gente que se agolpaba al lado y lado de las calles gritándole: Libertador, libertador (2).

En la película de Triana el hecho de mostrar tanta confusión es muy sugerente (tanto en la escena descrita con el presidente como en la escena en que los militares que intentan hacer el rescate de Santiago empiezan a llamarlo unas veces por su nombre y otras por el nombre de Bolívar). La explicación que le da Triana a Orlando Mora (2009) en una entrevista es que tal confusión es parte de la situación que se vive en Colombia en el 2001. Desde su perspectiva, los índices de violencia social han llevado a los ciudadanos a pensar que lo mejor sería seguir apostándole a la idea de realizar la utopía del sueño irrealizado de Bolívar si quieren construir una mejor nación. En palabras de Triana: "por eso me pareció sugestivo hacer de pronto una película sin posición, en el sentido de no tomar partido por alguien sino tomar partido por el sueño, por la utopía, por una idea de construcción de una patria posible, y de una manera catártica mostrar este circo un poco sangriento en que vivimos" (Mora, 2001: 6).

La representación quijotesca de Bolívar aparece entonces como una opción para una situación de violencia e inseguridad, ya que ayuda a mantener una ilusión, la de que en algún momento se creará una patria mejor. El mundo ideal de Santiago se puede ver metafóricamente como el mundo ideal del Quijote, en donde a través del loco se echarán a la hoguera los viejos escritos. En este caso, a la hoguera irían los escritos históricos en torno a la nación colombiana marcada por distintas épocas de violencia social, y los ciudadanos lucharán por una nación mejor, aunque sujetos como Santiago se tengan que dar contra los molinos de viento.

Examinando este tema con más profundidad, se observará que Santiago Miranda se puede relacionar con el Quijote no sólo por su actuación, sino por lo que el uso del intertexto entre historia y ficción implica. Se debe tener en cuenta que la película comienza con la escena en donde Santiago Miranda, reflexionando sobre su papel protagónico de representar a Bolívar, mira un crucifijo que tiene al frente y dice: "los tres grandes majaderos de la historia: Jesucristo, Don Quijote y yo", mientras se dirige a la sala de rodaje. Esta mención indica que todos ellos han representado imaginarios utópicos. En el caso de Bolívar, representar una unidad nacional estable ha sido una utopía, y como tal, esa unidad ha sido fragmentada, como se ve en 
la película, a través de los diferentes bolívares que se representan. Pero, además, Bolívar representa una unidad nacional en crisis por la amenaza de su agotamiento frente a la globalización y la fuerte agencia de los medios de comunicación.

La frase que sirve como punto de partida anuncia que de una u otra manera habrá una relación entre las acciones que Santiago va a emprender y las que realizaron Jesucristo y Don Quijote en su sueño por crear un mundo mejor. La mención que el actor hace de Jesucristo tomará valor al final de la película cuando, en su intento por salvar al pueblo colombiano, Santiago muere en medio de un combate entre el ejército nacional y la guerrilla. De este modo, Santiago/ Bolívar, al igual que Jesucristo, termina perdiendo su vida movido por el deseo de salvar a su pueblo. En la interacción historia-ficción hay que anotar que la frase inicial que menciona Santiago, haciendo referencia al Quijote, no surge al azar.

Según lo han anotado Santiago Díaz Piedrahita (2007) y Miguel de Unamuno (1983) dicha frase -que dice Santiago Miranda al inicio de la película- la pronunció Bolívar días antes de morir. Para estos autores, esta mención al personaje de Cervantes la hizo Bolívar un día que leía el Quijote y reflexionaba sobre sus propias acciones en la gesta libertaria, en uno de los últimos días de su vida, cuando se encontraba en la Quinta de San Pedro Alejandrino, el lugar en el que falleció. Esto para indicar que, además de la interacción ficciónrealidad que se mencionará en la influencia que Triana tuvo al crear su personaje, también existe una interacción ficción-realidad en el contraste que se hace entre los textos históricos y esta producción ficcional.

Otra coincidencia que guarda Santiago con Don Quijote es cómo ambos personajes actúan debido a su estado sicológico, al tener una aparente confusión entre los hechos de la vida real y los fantásticos, y cómo asumen el gran reto de enfrentarse a las estructuras políticas y sociales ya establecidas. En el Quijote, su locura le sirve al hidalgo para enfrentarse con diferentes sistemas políticos o sociales: así cuestiona el sistema académico por medio del estudiante de Salamanca; la Iglesia y el sistema legal, por medio de los galeotes; la corte, por medio de los duques y las princesas que quiere rescatar. Santiago, por su parte, se vale de su locura para enfrentar los estamentos gubernamentales, los medios de comunicación, los grupos contrainsurgentes y los estamentos educativos.

Por último, hay que agregar que Santiago coincide con Don Quijote en los hechos que realiza, al ser estos una respuesta a lo que otros 
textos han escrito. La diferencia aparente está en el tipo de escritura que estos dos personajes revisan. Santiago Miranda cuestiona los escritos hechos en torno a la vida de Bolívar y sus acciones, partiendo de los textos de historia nacional, que aparecen como una escritura fidedigna y objetiva, ya que han sido hechos por biógrafos e historiadores. Don Quijote, en su revisión de los textos escritos, se concentra en las escenas descritas en otras obras ficcionales, como lo son los poemas de Garcilaso de la Vega, o en el Amadís de Gaula, entre otros. En ese sentido, el interés de Santiago difiere de los intereses de Don Quijote en cuanto su revisión gira en torno a la escritura histórica y no a la ficcional. No obstante, al demostrar poco a poco que la escritura histórica se ha construido a partir de intereses particulares, desde la teatralidad con que Santiago asume los escritos históricos los hace ver como si fueran mera ficción.

Al igual que el Quijote, desde su revisión a la escritura y a lo que acontece en su entorno, Santiago intenta romper ciertos esquemas sociales de comportamiento, en el que los ciudadanos que no los sigan son tildados de locos. Muestra de esta actitud es toda la inestabilidad que se genera en la nación porque Santiago no se acogió a los lineamientos que le dio el presidente, cuando estaban en el barco secuestrados por los guerrilleros. Como consecuencia de sus acciones, Santiago, al igual que Don Quijote, no llega a un final feliz. Así la réplica del Quijote que hace Santiago, al querer ser Bolívar, como una vez el caballero andante quiso hacer del Amadís de Gaula, muestra que una unidad nacional basada en su imagen libertaria no es sostenible.

Para el propio realizador, Triana, lo que más le impactó no es que un actor pareciera desquiciado al haberse apropiado en extremo de su rol, sino que el público percibiera a un actor como al verdadero Bolívar (tal y como los duques le hacían creer a Don Quijote que él era en realidad un caballero andante). Para corroborar su idea en torno a cómo el público sustenta la locura de Santiago, Triana presenta una escena en que una encuesta nacional da como resultado que más del ochenta por ciento de la población no cree que Santiago esté loco. La relación ficción-realidad con que construye su personaje principal busca mostrar que existen códigos sociales que deben cambiarse, y esto lo muestra en la manera cómo el público recibe a Santiago, depositando en él su confianza. A manera de crítica social, en su Don Quijote, Cervantes mostraba también un público que simulaba seguir las acciones de su loco caballero andante. De esta manera proponía romper las reglas sociales a través de un personaje que no puede distinguir entre su realidad y la realidad de los caballeros andantes que encuentra en sus novelas de caballería. 
Como complemento de esta irrupción en los esquemas sociales, hay otros personajes que siguen a Don Quijote en sus locuras, haciéndole creer que en realidad él es un caballero andante, como se ve en el episodio de los condes y del cura disfrazado. Por su parte, en Bolívar soy yo la relación ficción-realidad se ilustra a través de un actor que parece no distinguir entre su vida y la vida del personaje que representa, pero también desde un público que lo sigue como si fuera Bolívar. En el caso de la película de Triana, la incapacidad del público contemporáneo de diferenciar entre la realidad y la ficción muestra cuánto han permeado los medios de comunicación en la sociedad colombiana contemporánea. En ese sentido, el interés del público por un Bolívar que representa una unidad nacional estable y genera un sentido de pertenencia en torno a una soberanía nacional se hace de lado frente a la gran influencia mediática que permite disimular la idea del loco actor que se cree Bolívar.

La confusión de Santiago y del público se juntan en un contexto en donde es difícil distinguir lo real de la representación montada a través de un guion, porque, tal y como se aprecia con Santiago, la idea no es que él sea Bolívar, sino que parezca serlo. Esta idea guarda un mensaje subyacente con respecto a si lo que vemos en las noticias es lo que pasa en la realidad, o es lo que queremos ver, influenciados por las mismas representaciones que muestran los medios. Desde una representación en la que no se sabe si Santiago actúa como si sufriera un trastorno sicológico, o si en realidad sí está afectado, Santiago alterna su rol histórico en parecer unas veces como un hombre lúcido y coherente, y en otras no tanto. Este aspecto es supremamente importante, ya que la actuación de Santiago, amparándose en esa supuesta demencia, genera una ambivalencia en cuanto a la revisión del discurso histórico.

La estrategia que Triana utiliza para posicionar la nueva representación de Bolívar es reescribir sobre la historia misma, haciendo uso de la imagen que prima en el imaginario colectivo. Por una parte, Santiago parte de la investidura militar, caballo y espada, y resaltando ciertos momentos específicos narrados por los textos de historia con sus proclamas y frases célebres. Pero, igualmente, Santiago revisa la historia nacional desde la ficción misma, volviendo a una imagen humanizada. Por lo tanto, sirve para revisar tanto el discurso histórico como el ficcional, no sólo desde su rol quijotesco, sino también desde el mismo contexto colombiano en el que se enmarca esta obra. 
La verdad histórica es cuestionada desde el texto de Triana a partir de un actor que revisa constantemente el discurso escrito en torno a Simón Bolívar mientras propone mostrar cómo el verdadero Bolívar podría ser sólo un personaje fundamentado en la teatralidad. Desde la representación que Triana hace de Bolívar, Santiago aparece falsamente como una luz de esperanza para reestructurar el orden nacional. Prueba de esto es la poca solución que Santiago les da a representantes del gobierno, como el presidente, miembros de un grupo insurgente y ciudadanos del común que enfrentan conflictos sociales y políticos del momento. Hay varios episodios en la película donde Santiago es abordado, ya sea por un grupo de niños de una escuela primaria, para que les solucione situaciones de su escuela, o buscado por sus vecinos, que se le acercan para que les ayude a solucionar las dificultades de su barrio.

De este modo, Bolívar, visto como un personaje humanizado por la ficción, cuestiona la verdad sobre la historia nacional de Colombia desde un presente extensivo y afín al público que sigue a Santiago/ Bolívar. La manera en que Triana usa el texto para hacer este cuestionamiento es ilustrando que la imagen de Bolívar construida desde medios de comunicación, como el cine, es una imagen levanta mediante una farsa que conlleva a mantener la ilusión de una patria mejor. Desde la percepción que podría tener el público en torno a un actor confundido, muestra la necesidad de crear un personaje que permita transformar esa imagen de un Bolívar que representa la unidad en uno que tenga un nuevo significado desde la afinidad que se pueda dar entre Bolívar como personaje histórico y los ciudadanos que le siguen.

Bolívar es visto, desde la actuación quijotesca de Santiago, como un símbolo al que se le ha transformado en instrumento por parte de los medios de comunicación. Bolívar, como símbolo, es rescatado para plantear nuevas opciones de lo que debe ser una nación que se enfrenta a la globalización y en la cual la influencia mediática ha permeado todas las esferas sociales. La importancia del rescate que resaltan las autoridades encargadas del caso es entonces no hacerle daño al símbolo. Aunque los miembros de la policía nacional sepan que Santiago no es Bolívar, el general que dirige la misión de rescate sugiere que hay que realizar esta labor sin poner en riesgo la vida de Bolívar. La razón que da es que si hay una falla y muere Santiago eso sería como matar a Bolívar, y no se puede matar a un símbolo nacional, porque "las consecuencias de asesinar a un símbolo son tan graves como contraproducentes". En este sentido, Triana corre el riesgo al final de la película de asesinar a Bolívar, y por lo tanto, de terminar con la imagen simbólica del Bolívar libertario que representa la unidad 
nacional. Su propuesta apunta a una reconfiguración total de Bolívar, dejando de lado tanto la imagen libertaria de la historiografía, como la imagen humanizada que han creado varios textos literarios.

La necesidad de crear un héroe nacional se muestra en la película como una coyuntura política que no importa cuán real sea la imagen que de él se construya, sino qué resultados puede arrojar. Como ejemplo de esta situación, tenemos la escena cuando los miembros de un grupo armado, que se ha subido al barco para seguir a Bolívar, afirman que su interés al estar allí es brindarle un tributo a su símbolo, con quien se sienten altamente identificados. Los miembros del grupo armado saben que Santiago no es Bolívar, pero fingen ver en el actor disfrazado al líder que, según ellos, da inicio a su movimiento. Su finalidad es en realidad, como se aprecia en el desarrollo de la película, atraer los medios de comunicación para así poder expresar sus verdaderas ideas a la nación colombiana. Llegan a expresar que no importa que Santiago esté desquiciado: lo que les interesa es lo que él representa. Tal apropiación es evidente cuando se refieren a Santiago unas veces como "mi general", "mi Libertador" o como "nuestro símbolo", dando a entender que es así como lo quieren ver, aunque sepan que no lo es.

Cuando en la escena pre-final Santiago insiste en escribir su historia, uno de los miembros de la guerrilla dice: "el símbolo sigue escribiendo". Como consecuencia, se aprecia que, aunque la imagen de Bolívar en la figura de Santiago no sea certera, los miembros del grupo armado dicen acogerlo como tal, más que todo porque les permitirá mostrarse no sólo en Colombia, sino internacionalmente. En dicha escena uno de los guerrilleros le responde al presidente que la farsa que representaban en torno a Bolívar ya se terminó. Esto ocurre cuando el presidente pregunta: “¿Dónde está Bolívar?”, indicándole así que para nada ellos habían creído que Santiago fuera Bolívar o que los representara, sino que su imagen les había sido útil para poder ganar un reconocimiento a nivel nacional.

Como puede verse al final de la película, ante el intento fallido que tiene el grupo armado al secuestrar a Santiago, por no poder secuestrar a todos los presidentes bolivarianos, y no poder hacerle un juicio al presidente de la República, se evidencia que Bolívar ya no representa una estabilidad para las ideas que el grupo sostiene. Bolívar entonces se transforma, por medio del fracaso del grupo guerrillero, en el símbolo de una inestabilidad que sólo finalizaría con su desaparición. El retrueno de las bombas y los enfrentamientos entre ejército y guerrilla que se ven en la escena final buscan quedarse en la retina del espectador, que debe juntar el principio con el final 
y proyectarlos a la utopía propuesta por Triana de conformar una patria mejor.

\section{Medios de comunicación y construcción de una imagen}

Un aspecto que merece ser analizado es la intervención de los medios de comunicación a lo largo de toda la película. Para empezar, hay que señalar que la trama de la película se sustenta todo el tiempo en el valor que los medios de comunicación le dan a la apropiación de Bolívar que hace Santiago Miranda. Recordemos que la película comienza con la filmación de una telenovela que no llega a su capítulo final, porque Santiago Miranda abandona su rol de protagonista. Ante este hecho, el curso de la película gira en torno a lo que hace Santiago. Tramas que enmarcan varias sub-tramas dentro de la trama principal. En principio se podría pensar que la historia principal es la que se debe desarrollar en la telenovela que filma Santiago, donde aparece como un Don Juan. No obstante, a lo largo de la película se observa que la historia principal es la vida de Bolívar protagonizada por Santiago Miranda desde la caracterización que hace un actor enloquecido.

En la idea de buscar un mejor final para su historia, la película empieza implicando que la trama principal que se mostrará tiene que ver con el valor que Bolívar tiene como héroe y símbolo nacional. Mientras Santiago comienza a interactuar con distintos ciudadanos y gobernantes al presentarse como Bolívar, su historia empieza a ser transmitida a través de los noticieros nacionales. En este punto, el público empieza a hacer parte también de la historia de Santiago Miranda al responder varias encuestas nacionales en las que se pregunta si los colombianos apoyan la actitud del actor enloquecido o no. La obra de Triana, sarcásticamente, denota que sorpresivamente las encuestas muestran como resultado que los ciudadanos que siguen la serie sí brindan su apoyo a Santiago Miranda, ya que el público también lo percibe como Bolívar mismo y como un hombre sano mentalmente. Se observa, pues, que en la representación de Bolívar en este filme, los medios juegan un papel muy importante. Primero, la representación que se ha hecho de Bolívar ha sido posible desde el cine como medio de comunicación; pero, además, la historia de Santiago se vuelve de interés nacional porque es transmitida televisivamente para seguir las acciones de Bolívar.

La transmisión televisiva de lo que hace Santiago Miranda apunta a crear verosimilitud. La presencia del cine y la televisión como parte de la trama sirve para mostrar cómo lo mediático crea unas imágenes 
que se presentan de una manera, pero que de igual modo han podido ser creadas de otra. La reproducción de la imagen construida de Bolívar juega mucho con la idea del "ser" y "parecer". Santiago no es Bolívar, pero al actuar como si lo fuera, el público lo asume como tal, aunque sepa que no lo es. Esta representación del público mostrada por Triana es bastante problemática en cuanto evidencia la relación del público con los personajes creados por los medios bajo una incapacidad crítica: el público colombiano sigue creyendo en un Bolívar que en realidad es sólo Santiago Miranda.

Para el sociólogo francés Jean Baudrillard (2004), la posibilidad de que una apariencia no sea real no indica que la imagen presentada no se perciba como certera por los receptores que la ven a través de un medio de comunicación audiovisual. En el momento en que se instituye una imagen mediática se implica que ésta no se hace como una parodia de una realidad existente, sino como una que reemplace los signos interpretativos de dicha realidad: "It is no longer a question of imitation, nor a reduplication, nor even of parody. It is rather a question of substituting signs of the real for the real itself [...]" (366). El protagonista de Bolívar soy yo, al presentarse desde la nueva apropiación que hace Santiago Miranda, no pareciera estar parodiando a Bolívar como héroe, sino que se presenta como si él fuera el verdadero Bolívar que nadie hasta el momento había conocido.

Según lo ha anotado repetidas veces Santiago Miranda, la representación de Bolívar está basada en una farsa que ha intentado presentarse como la realidad: el Bolívar de la telenovela, el Bolívar del grupo guerrillero, el Bolívar que recibe el presidente. Los medios lo que hacen es reiterar la farsa generada por la imagen. El discurso de los medios pasa a remplazar el discurso histórico. Al final de la película, la proyección mediática del personaje se patentiza cuando aparece un camarógrafo haciendo una señal de corte. La imagen proyectada muestra a Bolívar como una representación mediada. La señal de corte indica que todo ha sido un montaje del noticiero que supuestamente seguía las acciones de Santiago, cuando lo que hacía era cumplir con una parte de la película. La petición de corte hecha por Santiago al principio y luego corroborada al final implica que la grabación de la telenovela que se había suspendido hacía parte de un escenario y nada más. El simulacro planteado por los medios funciona como un paralelo del simulacro de la imagen creada por la historiografía, por los grupos de izquierda, por los gobernantes y por los ciudadanos. La presencia mediática coincide desde el montaje, o la farsa, como afirmaba Santiago Miranda, con la anomia del gobierno que sólo busca presentar un Bolívar que pueda 
leer discursos escritos por otros, y que no se atreve a enfrentar a la guerrilla por no destruir el Bolívar que prima en el imaginario social.

\section{Consideraciones finales}

Aunando los tres ejes centrales aquí planteados como hilo conductor de la revisión cinematográfica de la imagen de Bolívar, se subraya que el filme de Jorge Alí Triana, Bolívar soy yo, constituye una caracterización personal de Bolívar, basándose en los rasgos de una humanidad más doliente, más visceral: pathos. Este filme plantea, además, una conexión entre Bolívar y la nación mediante las situaciones vividas por los ciudadanos. El aporte particular consiste en que el paralelo trazado entre Bolívar y la nación se da a partir de un discurso fragmentado y una narración onírica que conlleva a pensar en varias representaciones de Bolívar. Esta obra ficcional responde a un presente histórico en el que la idea de una "unidad nacional" asociada con un Bolívar heroico y monumental, representante de una nación soberana y estable, ha perdido valor. Bolívar es visto metafóricamente como un héroe cambiante al que se le sigue adaptando a distintos momentos socio-políticos, y las situaciones de conflicto del presente siguen siendo vistas como heredadas de su padre fundador.

Independientemente de cuál sea el género, grupo humano o la condición socio-económica de muchos ciudadanos civiles y gobernantes, la imagen de Bolívar vista por la ficción puede ser pensada bajo una nueva convocación ciudadana. Por tal motivo, a Bolívar, "El Libertador", se le transforma en un héroe que invita a los lectores a pensar en su rol como agente de cambio dentro del ámbito nacional. En otros casos, será relacionado con un sueño político que aún está por formularse. En cualquiera de los casos, es importante reconocer que, sea cual fuere la forma en que se le enuncie, su imagen ganará un nuevo reconocimiento con la transformación que los textos ficcionales han hecho de la imagen instaurada por la historiografía nacional. La nueva decantación estética de Bolívar hecha por el cine y la literatura contemporánea postula, directa o indirectamente, una nueva imagen en busca de una identidad nacional desde la diversidad que implican sus ciudadanos y acorde a los cambios socioculturales en que les corresponda vivir.

\section{Bibliografía}

Arciniegas, G. (1984). Bolívar y la revolución. Bogotá: Planeta.

Baudrillard, J. (2004). "Simulacra Simulation". En Rivkin Julie \& Michael Ryan. (Eds.). Literary Theory: An Anthology. Oxford: 
Blackwell.Bolívar, S. (1965). Carta de Jamaica. Bogotá: Ministerio de Educación,. (1975). "Discurso ante el Congreso de Angostura". En Escritos políticos. Madrid: Alianza Editorial.

Carrera Damas, G. (1989). El culto a Bolívarr. Esbozo para un estudio de la historia de las ideas en Venezuela. Caracas: Grijalbo.

Conway, C. (2003). The Cult of Bolívar in Latin American Literature. Gainesville: University Press of Florida.

De Unamuno, M. (1983). "Don Quijote y Bolívar", Revista de Historia de América, no 95 (Enero), pp. 131-137.

Díaz Piedrahita, S. (2007). "Algunas anécdotas del Libertador", Credencial Historia, $\mathrm{n}^{\circ}$ 212. Consultado en http://www. banrepcultural.org/blaavirtual/revistas/credencial/ agosto2007/anecdotaslibertador.htm

Eco, U. (1984). Obra abierta. Barcelona: Planeta De Agostini.

Garzón, D. (2002). "El fue Bolívar", Semana, n¹046, Bogotá, p. 1.

Laclau. E. (2005). On Populist Reason. Nueva York: Verso.

Mora, O. (2003). "Bolívar soy yo: entre la razón y la locura", El ojo que piensa. Consultado en http://www.elojoquepiensa.udg. $\mathrm{mx} /$ espanol/00/cinejournal4/04.bolivar.html

Alí Triana, J. (2001). Bolívar soy yo. Dir. Jorge Alí Triana. DVD video. Ministerio de Cultura: Bogotá.

- (1982). "Bolívar, el hombre de las dificultades". En Revivamos nuestra historia. Documental audiovisual. Dir. Jorge Alí Triana. Academia Colombiana de Historia: Bogotá. 
